\title{
The effect of NACHRI children's hospital designation on outcome in pediatric malignant brain tumors
}

\author{
Daniel A. Donoho, MD, ${ }^{1}$ Timothy Wen, MD, ${ }^{2}$ Jonathan Liu, MD, ${ }^{2}$ Hosniya Zarabi, MD, ${ }^{3}$ \\ Eisha Christian, MD, ${ }^{1}$ Steven Cen, PhD, ${ }^{4,5}$ Gabriel Zada, MD, MS, ${ }^{1}$ J. Gordon McComb, MD, ${ }^{6}$ \\ Mark D. Krieger, MD, ${ }^{6}$ William J. Mack, MD, ${ }^{1}$ and Frank J. Attenello, MD ${ }^{1}$
}

${ }^{1}$ Department of Neurological Surgery, ${ }^{2}$ Keck School of Medicine, University of Southern California; Departments of ${ }^{4}$ Preventive Medicine and ${ }^{5}$ Radiology and ${ }^{6}$ Division of Neurosurgery, Department of Surgery, Children's Hospital of Los Angeles, California; and ${ }^{3}$ Department of Neurosurgery, Emory University School of Medicine, Atlanta, Georgia

\begin{abstract}
OBJECTIVE Although current pediatric neurosurgery guidelines encourage the treatment of pediatric malignant brain tumors at specialized centers such as pediatric hospitals, there are limited data in support of this recommendation. Previous studies suggest that children treated by higher-volume surgeons and higher-volume hospitals may have better outcomes, but the effect of treatment at dedicated children's hospitals has not been investigated.

METHODS The authors analyzed the Healthcare Cost and Utilization Project Kids' Inpatient Database (KID) from 2000-2009 and included all patients undergoing a craniotomy for malignant pediatric brain tumors based on ICD-9-CM codes. They investigated the effects of patient demographics, tumor location, admission type, and hospital factors on rates of routine discharge and mortality.

RESULTS From 2000 through 2009, 83.6\% of patients had routine discharges, and the in-hospital mortality rate was $1.3 \%$. In multivariate analysis, compared with children treated at an institution designated as a pediatric hospital by NACHRI (National Association of Children's Hospitals and Related Institutions), children receiving treatment at a pediatric unit within an adult hospital (OR $0.5, p<0.01)$ or a general hospital without a designated pediatric unit $(O R 0.4, p<$ 0.01 ) were less likely to have routine discharges. Treatment at a large hospital (> 400 beds; OR 1.8, $p=0.02$ ) and treatment at a teaching hospital (OR 1.7, $p=0.02)$ were independently associated with greater likelihood of routine discharge. However, patients transferred between facilities had a significantly decreased likelihood of routine discharge (OR 0.5, $p<0.01$ ) and an increased likelihood of mortality (OR 5.0, $p<0.01)$. Procedural volume was not associated with rate of routine discharge or mortality.
\end{abstract}

CONCLUSIONS These findings may have implications for planning systems of care for pediatric patients with malignant brain tumors. The authors hope to motivate future research into the specific factors that may lead to improved outcomes at designated pediatric hospitals.

https://thejns.org/doi/abs/10.3171/2017.1.PEDS16527

KEY WORDS malignant pediatric brain tumor; hospital designation; outcomes; oncology

$\mathrm{I}$ $\mathrm{N}$ the United States, more than 2000 children are diagnosed with a malignant central nervous system (CNS) tumor-defined as any lesion of WHO Grade II, III, or IV-each year. ${ }^{35}$ The vast majority of these tumors $(90 \%)$ are localized within the brain parenchyma. ${ }^{35}$ Current pediatric neurosurgery guidelines recommend that treatment of these CNS tumors should take place at specialized centers, including pediatric hospitals, with higher volumes of pediatric tumor cases, specific training, and well-established treatment protocols. ${ }^{22}$ Nevertheless, available data in support of this recommendation are limited.
In other fields, specialty hospitals treating a single patient population have been shown to provide improved quality of care by concentrating resources and expertise.,12,13,29 Patients undergoing complex cancer, cardiovascular, and neurosurgical procedures at these facilities have been shown to have decreased rates of morbidity and mortality. ${ }^{5,11,21,25}$ This effect is likely due to a variety of factors, including the concentration of specialized resources with high fixed/startup costs, the development of expertise through increased procedural volume, and the training and retention of specialists. ${ }^{6,20,24,37}$ 
The National Association of Children's Hospitals and Related Institutions (NACHRI) recognizes over 220 specialized pediatric hospitals. To date, no large-scale national studies have examined the effects of pediatric hospital designation on the outcomes of neurosurgical procedures for malignant pediatric brain tumors. For the purpose of assessing this relationship, a national database may be uniquely useful. The largest source of nationwide patientlevel pediatric data is the Healthcare Cost and Utilization Project Kids' Inpatient Database (KID). The KID is published every 3 years using a subset of the Nationwide Inpatient Sample. KID data are compiled from pediatric patient discharges throughout the United States. The current KID dataset contains data from several million discharges annually and includes patient demographics, tumor location, admission type, and hospital factors. Using appropriate weighting, the KID data can be used to estimate 7 million discharges per year. Accordingly, the KID provides an important window into the delivery of pediatric health care in the United States. Other databases that can be used for the analysis of pediatric data include the Nationwide Inpatient Sample, individual state inpatient databases, private insurance data sets such as MarketScan and even pediatric-focused data sets. Each type of database has its own attendant strengths and weaknesses. For example, the Pediatric Health Information System (PHIS) is a quarterly database that includes data from 45 children's hospitals that are part of the Children's Hospital Association. Because we sought to compare outcomes across a broad range of payers and institutions throughout the United States, we felt that the KID would be best suited to answer our research question.

We sought to explore the relationship between hospital designation (children's hospital, pediatric ward in a general hospital, or general hospital without pediatric ward) and patient outcomes (discharge type, mortality). We hypothesized that pediatric patients with malignant brain tumors undergoing neurosurgical procedures at specialty pediatric hospitals are more likely to have routine discharges and less likely to have died during their hospitalization than those undergoing similar procedures at nonspecialized centers.

\section{Methods \\ Data Sample}

This study used discharge information abstracted from the KID from 2000, 2003, 2006, and 2009. The KID is assembled every 3 years by the Agency for Healthcare Quality and Research's Healthcare Cost and Utilization Project $(2000,2003,2006,2009){ }^{2}$ The KID is a stratified random sample of $10 \%$ of uncomplicated in-hospital births and $80 \%$ of pediatric discharges from each nonfederal, nonrehabilitation hospital in participating states. From 2000 through 2009, the KID data sets included between $2,516,833$ and 3,407,146 discharges, with weights allowing the estimation of 7,291,032-7,558,812 discharges. The 2009 KID included 44 participating states. ${ }^{2}$ The KID's large sample size allows for analysis of uncommon conditions, such as pediatric malignant brain tumors. Additionally, the sampling method of KID includes discharge weights that allow for national estimates to be calculated. Weights are calculated by stratification of hospitals by region, urban location, teaching status, size (based on number of beds), ownership, and hospital type. Discharge weights for patients other than healthy newborns (i.e., all of the patients in this study) are calculated by dividing the total number of children in the American Hospital Association Survey by the number of adjusted discharges in the sampling frame multiplied by the frame sampling rate, and then multiplying by 4 divided by the number of quarters for which each hospital participated in the KID in the study year. The purpose of the KID is to permit nationallevel analysis of patterns of hospital use, outcomes, and charges.

\section{Study Cohort}

Patients were selected based on International Classification of Diseases, Ninth Edition, Clinical Modification (ICD-9-CM) codes for the diagnosis of malignant brain tumor (191.1-191.9) and an excision of a brain tumor (01.59). Documented tumor location was categorized (frontal, temporal, parietal, occipital, intraventricular, cerebellum, brainstem). Patient factors, such as race (white, black, Hispanic, Asian Pacific Islander, Native American, other), payer information (Medicare, Medicaid, private insurance, self-pay, no charge, other), and sex (male, female) were coded as categorical variables in KID. Age was converted from continuous into a categorical variable (age categories: < 1 year, 1-4 years, 5-9 years, 10-17 years, 18-20 years). KID also includes hospital factors, such as hospital size (small, medium, large, representing $<200$ beds, 200-400 beds, and $>400$ beds, respectively), hospital region (Northeast, Midwest, South, West), hospital teaching status (teaching, nonteaching), and hospital location (urban, rural). Hospital type based on the National Association of Pediatric Hospitals and Related Institutions (NACHRI) was recoded as "not identified as a pediatric hospital by NACHRI," "identified as a pediatric hospital by NACHRI," or "identified as a pediatric unit in a general hospital by NACHRI." Hospitals were further characterized by procedural volume, with high-volume centers being above the 90th percentile and low-volume centers representing those at or below the 90th percentile. Finally, we controlled for admission variables such as admission source (emergency room, outside hospital transfer, routine) and admission type (emergent, urgent, or elective as defined by KID database coding standards) in our analysis.

\section{Statistical Analysis}

This study used 2 primary outcomes to measure discharge quality: routine discharge and inpatient death. These were recoded as dichotomous variables for analysis (routine discharge vs nonroutine discharge, inpatient death vs alive at discharge). Routine discharge is defined as discharge to home. Two multivariate logistic regression models using survey-adjusted generalized estimating equations were fit to model these outcomes with 1 primary predictor, hospital type, and adjusting for patient demographics (including insurance status), tumor location (based on malig- 
TABLE 1. Patient, admission, and hospital characteristics

\begin{tabular}{|c|c|c|}
\hline Variable & No. of Discharges & $\%$ \\
\hline \multicolumn{3}{|l|}{ Payer information } \\
\hline Medicare & DS & 0 \\
\hline Medicaid & 2510 & 26.8 \\
\hline Private insurance & 6063 & 64.8 \\
\hline Self-pay & 244 & 2.6 \\
\hline Other & 480 & 5.1 \\
\hline Missing & 34 & 0.4 \\
\hline \multicolumn{3}{|l|}{ Race } \\
\hline White & 5017 & 56.6 \\
\hline Black & 690 & 7.4 \\
\hline Hispanic & 1249 & 13.4 \\
\hline Asian Pacific Islander & 198 & 2.1 \\
\hline Other & 368 & 3.9 \\
\hline Missing & 1810 & 19.3 \\
\hline \multicolumn{3}{|l|}{ Sex } \\
\hline Male & 4170 & 44.5 \\
\hline Female & 5103 & 54.5 \\
\hline Missing & 52 & 0.6 \\
\hline \multicolumn{3}{|l|}{ Age } \\
\hline$<1 \mathrm{yr}$ & 425 & 4.5 \\
\hline $1-4$ yrs & 2318 & 24.8 \\
\hline $5-9$ yrs & 2428 & 25.9 \\
\hline $10-17$ yrs & 3229 & 34.5 \\
\hline $18-20$ yrs & 960 & 10.3 \\
\hline \multicolumn{3}{|l|}{ Tumor location } \\
\hline Cerebrum & 676 & 7.2 \\
\hline Frontal & 994 & 10.6 \\
\hline Temporal & 826 & 8.8 \\
\hline Parietal & 499 & 5.3 \\
\hline Occipital & 302 & 3.2 \\
\hline Ventricles & 1113 & 11.9 \\
\hline Cerebellum & 2165 & 23.1 \\
\hline Brainstem & 560 & 6.0 \\
\hline Other location in brain & 1156 & 12.4 \\
\hline Brain, unspecified & 1068 & 11.4 \\
\hline \multicolumn{3}{|l|}{ Hospital type } \\
\hline Children's hospital & 3523 & 37.6 \\
\hline General hospital w/ children's unit & 3904 & 41.7 \\
\hline General hospital w/o children's unit & 1400 & 15.0 \\
\hline Missing & 534 & 5.7 \\
\hline \multicolumn{3}{|l|}{ Hospital size } \\
\hline Small (<200 beds) & 1215 & 13.0 \\
\hline Medium (200-400 beds) & 2504 & 26.8 \\
\hline Large (>400 beds) & 5233 & 55.9 \\
\hline Missing & 408 & 4.4 \\
\hline \multicolumn{3}{|l|}{ Hospital region } \\
\hline Northeast & 1957 & 20.9 \\
\hline Midwest & 1861 & 19.9 \\
\hline South & 3063 & 32.7 \\
\hline West & 2480 & 26.5 \\
\hline
\end{tabular}

CONTINUED IN NEXT COLUMN
» CONTINUED FROM PREVIOUS COLUMN

TABLE 1. Patient, admission, and hospital characteristics

\begin{tabular}{|c|c|c|}
\hline Variable & No. of Discharges & $\%$ \\
\hline \multicolumn{3}{|l|}{ Hospital teaching status } \\
\hline Nonteaching & 422 & 4.5 \\
\hline Teaching & 8530 & 91.1 \\
\hline Missing & 408 & 4.4 \\
\hline \multicolumn{3}{|l|}{ Hospital location } \\
\hline Rural & 108 & 1.2 \\
\hline Urban & 8844 & 94.5 \\
\hline Missing & 408 & 4.4 \\
\hline \multicolumn{3}{|l|}{ Admission source } \\
\hline ER & 1802 & 19.3 \\
\hline Another hospital & 871 & 9.3 \\
\hline Routine & 4873 & 52.1 \\
\hline Missing & 1813 & 19.4 \\
\hline \multicolumn{3}{|l|}{ Admission type } \\
\hline Emergency & 2720 & 29.1 \\
\hline Urgent & 1651 & 17.6 \\
\hline Elective & 3563 & 38.1 \\
\hline Missing & 1397 & 14.9 \\
\hline \multicolumn{3}{|l|}{ Procedure vol quartiles } \\
\hline 1st (s1 cases/yr) & 384 & 4.1 \\
\hline 2nd (1-2 cases/yr) & 305 & 3.3 \\
\hline 3rd (2-4 cases/yr) & 1038 & 11.1 \\
\hline 4th (>4 cases/yr) & 7632 & 81.5 \\
\hline \multicolumn{3}{|l|}{ Procedure vol (children's hospitals) } \\
\hline $\begin{array}{l}\text { Below mean children's hospital vol } \\
\text { ( } \leq 15 \text { cases/yr) }\end{array}$ & 5196 & 55.5 \\
\hline $\begin{array}{l}\text { Above mean children's hospital vol } \\
\text { (>15 cases/yr) }\end{array}$ & 4163 & 44.5 \\
\hline
\end{tabular}

$\mathrm{DS}=$ data suppressed; $\mathrm{ER}=$ emergency room.

nant tumor ICD-9-CM code), admission type, and hospital factors. Our primary exposure of interest was the type of pediatric hospital (pediatric hospital, pediatric unit in a general hospital, hospital without specialized pediatric unit).

Statistical significance was predetermined as $p<0.05$. All descriptive univariate and multivariate analyses were conducted in SAS 9.3 (SAS Institute).

\section{Results}

\section{Study Cohort Demographics}

Over the 4 years for which KID's data are available (2000, 2003, 2006, and 2009) 9360 children underwent craniotomy for a malignant CNS tumor. The majority of patients were white $(56.6 \%)$, and there was a slight female predominance $(54.5 \%)$. As expected in this age group, the most common location for tumors was the cerebellum $(23.1 \%)$, followed by the ventricles $(11.9 \%)$ and the frontal lobes (10.6\%) (Table 1).

Most patients were discharged from specialized pediatric units $(41.7 \%)$ or pediatric hospitals (37.6\%). Almost 
TABLE 2. Predictors of routine discharge among pediatric patients with malignant CNS tumors

\begin{tabular}{|c|c|c|c|}
\hline Variable & OR & $95 \% \mathrm{Cl}$ & $\mathrm{p}$ Value \\
\hline \multicolumn{4}{|l|}{ Payer information } \\
\hline Private insurance & Ref & & \\
\hline Medicaid & 0.9 & $0.8-1.1$ & 0.48 \\
\hline Self-pay & 1.2 & $0.7-2.2$ & 0.49 \\
\hline Other & 1.3 & $0.8-1.9$ & 0.32 \\
\hline \multicolumn{4}{|l|}{ Race } \\
\hline White & Ref & & \\
\hline Black & 0.8 & $0.6-1.1$ & 0.21 \\
\hline Hispanic & 0.9 & $0.7-1.1$ & 0.21 \\
\hline Asian Pacific Islander & 0.8 & $0.5-1.1$ & 0.19 \\
\hline Other & 0.7 & $0.5-1.0$ & $0.04^{*}$ \\
\hline \multicolumn{4}{|l|}{ Female } \\
\hline Male & Ref & & \\
\hline Female & 1.0 & $0.9-1.2$ & 0.62 \\
\hline \multicolumn{4}{|l|}{ Age } \\
\hline$<1 \mathrm{yr}$ & 0.6 & $0.4-1.0$ & $0.04^{*}$ \\
\hline $1-4$ yrs & 1.1 & $0.8-1.6$ & 0.56 \\
\hline $5-9$ yrs & 1.4 & $1.0-2.0$ & 0.06 \\
\hline $10-17$ yrs & 1.5 & $1.1-2.0$ & $0.02^{*}$ \\
\hline $18-20$ yrs & Ref & & \\
\hline \multicolumn{4}{|l|}{ Tumor location } \\
\hline Frontal & Ref & & \\
\hline Cerebrum (nonlobar) & 0.4 & $0.3-0.6$ & $<0.001^{*}$ \\
\hline Temporal & 1.0 & $0.6-1.6$ & 0.98 \\
\hline Parietal & 0.9 & $0.5-1.4$ & 0.56 \\
\hline Occipital & 0.6 & $0.3-1.2$ & 0.17 \\
\hline Ventricles & 0.3 & $0.2-0.5$ & $<0.001^{*}$ \\
\hline Cerebellum & 0.5 & $0.3-0.7$ & $<0.001^{*}$ \\
\hline Brainstem & 0.2 & $0.1-0.3$ & $<0.001^{*}$ \\
\hline Other location in brain & 0.4 & $0.3-0.6$ & $<0.001^{*}$ \\
\hline Brain, unspecified & 0.4 & $0.3-0.6$ & $<0.001^{*}$ \\
\hline \multicolumn{4}{|l|}{ Hospital type } \\
\hline Children's hospital & Ref & & \\
\hline General hospital w/o children's unit & 0.5 & $0.3-0.7$ & $<0.01^{*}$ \\
\hline General hospital w/ children's unit & 0.4 & $0.3-0.6$ & $<0.01^{*}$ \\
\hline \multicolumn{4}{|l|}{ Hospital size } \\
\hline Small (<200 beds) & Ref & & \\
\hline Medium (200-400 beds) & 1.3 & $0.8-1.9$ & 0.27 \\
\hline Large (>400 beds) & 1.8 & $1.1-2.9$ & $0.02^{*}$ \\
\hline \multicolumn{4}{|l|}{ Hospital region } \\
\hline Northeast & Ref & & \\
\hline Midwest & 2.5 & $1.7-3.7$ & $<0.01^{*}$ \\
\hline South & 2.1 & $1.6-2.8$ & $<0.01^{*}$ \\
\hline West & 1.6 & $1.1-2.3$ & $<0.01^{*}$ \\
\hline \multicolumn{4}{|l|}{ Hospital teaching status } \\
\hline Nonteaching & Ref & & \\
\hline Teaching & 1.7 & $1.1-2.6$ & 0.02 \\
\hline
\end{tabular}

» CONTINUED FROM PREVIOUS COLUMN

TABLE 2. Predictors of routine discharge among pediatric patients with malignant CNS tumors

\begin{tabular}{lccc}
\hline \multicolumn{1}{c}{ Variable } & OR & $95 \% \mathrm{Cl}$ & $\mathrm{p}$ Value \\
\hline Hospital location & & & \\
\hline Rural & Ref & & \\
\hline Urban & 1.1 & $0.4-3.0$ & 0.84 \\
\hline Admission source & & & \\
\hline Routine & Ref & & \\
\hline ER & 0.7 & $0.5-0.9$ & $<0.01^{*}$ \\
\hline Another hospital & 0.5 & $0.4-0.7$ & $<0.01^{*}$ \\
\hline Other health facility & 0.8 & $0.4-1.6$ & 0.51 \\
\hline Admission type & & & \\
\hline Elective & Ref & & \\
\hline Emergency & 0.7 & $0.5-0.9$ & $<0.01^{*}$ \\
\hline Urgent & 0.8 & $0.6-1.1$ & 0.25 \\
\hline Procedure vol quartile & & & \\
\hline 1st & Ref & & \\
\hline 2nd & 0.7 & $0.4-1.1$ & 0.13 \\
\hline 3rd & 0.7 & $0.4-1.1$ & 0.12 \\
\hline 4th & 0.9 & $0.6-1.4$ & 0.72 \\
\hline
\end{tabular}

Ref $=$ reference.

* Statistically significant $(p<0.05)$.

all patients were discharged from urban (94.5\%), teaching hospitals (91.1\%). With respect to admission source, most admissions were routine (52.1\%), including admissions at birth, admissions from clinic, and physician referrals. The most common type of admission was elective (38.1\%).

Among 9350 children for whom discharge information was available, 7824 children $(83.6 \%)$ had routine discharges and $1526(16.4 \%)$ had nonroutine discharges. There were 124 in-hospital deaths (1.3\%).

\section{Outcomes: Routine Discharge}

The results of our multivariate logistic regression model, including patient demographic, payer, hospital, and admission predictors of routine discharge, are presented in Table 2. Several patient factors were independently associated with risk of routine discharge. Compared with patients 18-20 years of age, patients under 1 year of age were less likely to be routinely discharged (OR 0.6, p = 0.03 ) while patients $10-17$ years of age were more likely to be routinely discharged (OR $1.5, \mathrm{p}=0.02)$. Compared with tumors in the frontal lobe, tumors located in the cerebellum (OR 0.5, p <0.001), brainstem (OR 0.2, p < 0.001), ventricles (OR $0.3, p<0.001)$, and other locations (cerebrum other than lobes OR $0.4, \mathrm{p}<0.001$, other location and location unspecified OR $0.4, \mathrm{p}<0.001$ ) were much less likely to have routine discharge.

Even after controlling for patient and admission factors, we found that several hospital factors were also significantly associated with rate of routine discharge. When compared with dedicated pediatric hospitals, general hospitals with pediatric units (OR $0.4, \mathrm{p}<0.01)$, and general (nonpediatric) hospitals (OR $0.5, \mathrm{p}<0.01$ ) were associated 
TABLE 3. Predictors of inpatient death among pediatric patients with malignant CNS tumors

\begin{tabular}{|c|c|c|c|}
\hline Variable & OR & $95 \% \mathrm{Cl}$ & $p$ Value \\
\hline \multicolumn{4}{|l|}{ Payer information } \\
\hline Private insurance & Ref & & \\
\hline Medicaid & 1.0 & $0.5-1.8$ & $>0.99$ \\
\hline Self-pay & 0.6 & $0.1-4.0$ & 0.61 \\
\hline Other & 0.7 & $0.2-1.9$ & 0.46 \\
\hline \multicolumn{4}{|l|}{ Race } \\
\hline White & Ref & & \\
\hline Black & 1.4 & $0.5-3.4$ & 0.52 \\
\hline Hispanic & 1.6 & $0.7-3.8$ & 0.24 \\
\hline Asian Pacific Islander & 3.4 & $1.1-10.2$ & $0.03^{*}$ \\
\hline Other & 1.1 & $0.3-4.2$ & 0.91 \\
\hline \multicolumn{4}{|l|}{ Sex } \\
\hline Male & Ref & & \\
\hline Female & 2.2 & $1.2-4.0$ & $<0.01$ \\
\hline \multicolumn{4}{|l|}{ Age } \\
\hline$<1 \mathrm{yr}$ & 6.3 & $0.7-61.8$ & 0.11 \\
\hline $1-4$ yrs old & 0.9 & $0.1-8.9$ & 0.92 \\
\hline $5-9$ yrs & 0.6 & $0.1-5.7$ & 0.65 \\
\hline $10-17$ yrs & 0.6 & $0.1-5.2$ & 0.63 \\
\hline $18-20$ yrs & Ref & & \\
\hline \multicolumn{4}{|l|}{ Tumor location } \\
\hline Frontal & Ref & & \\
\hline Cerebrum (nonlobar) & 0.6 & $0.1-3.8$ & 0.55 \\
\hline Temporal & 1.0 & $0.3-3.7$ & $>0.99$ \\
\hline Parietal & 1.5 & $0.3-7.2$ & 0.58 \\
\hline Occipital & 0.8 & $0.1-8.5$ & 0.86 \\
\hline Ventricles & 0.7 & $0.2-2.5$ & 0.55 \\
\hline Cerebellum & 1.7 & $0.4-6.9$ & 0.46 \\
\hline Brainstem & 2.8 & $0.7-10.6$ & 0.14 \\
\hline Other location in brain & 3.0 & $0.8-11.3$ & 0.11 \\
\hline Brain, unspecified & 1.7 & $0.4-7.0$ & 0.44 \\
\hline \multicolumn{4}{|l|}{ Hospital type } \\
\hline Not a children's hospital & 1.9 & $0.8-4.9$ & 0.15 \\
\hline Children's unit & 2.1 & $0.8-5.4$ & 0.12 \\
\hline Children's hospital & Ref & & \\
\hline \multicolumn{4}{|l|}{ Hospital size } \\
\hline Small (<200 beds) & Ref & & \\
\hline Medium (200-400 beds) & 0.6 & $0.2-1.3$ & 0.20 \\
\hline Large (>400 beds) & 0.4 & $0.2-1.1$ & 0.09 \\
\hline \multicolumn{4}{|l|}{ Hospital region } \\
\hline Northeast & Ref & & \\
\hline Midwest & 1.8 & $0.5-6.1$ & 0.37 \\
\hline South & 0.9 & $0.4-1.9$ & 0.71 \\
\hline West & 1.8 & $0.7-4.5$ & 0.22 \\
\hline \multicolumn{4}{|l|}{ Hospital teaching status } \\
\hline Nonteaching & Ref & & \\
\hline Teaching & 0.3 & $0.1-1.3$ & 0.11 \\
\hline
\end{tabular}

» CONTINUED FROM PREVIOUS COLUMN

TABLE 3. Predictors of inpatient death among pediatric patients with malignant CNS tumors

\begin{tabular}{lccc}
\hline \multicolumn{1}{c}{ Variable } & OR & $95 \% \mathrm{Cl}$ & p Value \\
\hline $\begin{array}{l}\text { Hospital location } \\
\text { Rural }\end{array}$ & Ref & & \\
\hline Urban & 0.4 & $0.0-5.7$ & 0.52 \\
\hline Admission source & & & \\
\hline Routine & Ref & & \\
\hline ER & 2.1 & $0.9-4.9$ & 0.07 \\
\hline Another hospital & 5.1 & $2.1-12.3$ & $<0.01^{*}$ \\
\hline Other health facility & 4.3 & $1.0-17.9$ & $0.05^{*}$ \\
\hline Admission type & & & \\
\hline Elective & Ref & & \\
\hline Emergency & 2.8 & $1.0-7.4$ & $0.04^{*}$ \\
\hline Urgent & 1.0 & $0.3-3.1$ & 0.96 \\
\hline Procedure vol quartile & & & \\
\hline 1st & Ref & & \\
\hline 2nd & 1.6 & $0.2-12.3$ & 0.65 \\
\hline 3rd & 1.3 & $0.1-12.9$ & 0.81 \\
\hline 4th & 2.4 & $0.2-22.6$ & 0.46 \\
\hline
\end{tabular}

* Statistically significant $(p<0.05)$.

with a significantly decreased likelihood of routine discharge. Even after controlling for other hospital, patient and admission factors, children treated at hospitals with more than 400 beds (OR 1.8, $\mathrm{p}=0.02)$ and teaching institutions (OR 1.7, $\mathrm{p}=0.02)$ were also more likely to have a routine discharge. We analyzed hospital volume using multiple methods, including as a continuous variable, by quartiles, and as a dichotomous variable (more than vs less than 15 cases per year and also above vs below the 90th percentile for volume). Higher-volume hospitals were not more likely to have routine discharges than lower-volume hospitals.

After controlling for patient and hospital factors, we found that admission factors were also associated with decreased rate of routine discharge. Compared with elective admissions, emergent admissions were less likely to be associated with routine discharges (OR 0.7, p < 0.01). Similarly, compared with routine admissions, patients admitted from the emergency room (OR 0.7, p < 0.01) and transferred from outside hospitals (OR 0.5, $\mathrm{p}<0.01$ ) were less likely to have routine discharges.

\section{Outcomes: Mortality}

The results of our multivariate logistic regression model, including patient, hospital, and admission predictors of inpatient mortality, are presented in Table 3.

Hospital factors, including size, teaching status, location, and volume, were not associated with mortality. After controlling for other patient, hospital, and admission factors, we found that pediatric specialty hospitals and pediatric units were not less likely to have inpatient deaths than nonpediatric hospitals. We analyzed hospital volume using multiple methods, including as a continuous vari- 
able, by quartiles, and as a dichotomous variable (more than vs less than 15 cases per year and also above vs below the 90th percentile for volume). Higher-volume hospitals were not less likely to have inpatient deaths than lowervolume hospitals

Several admissions factors were associated with increased likelihood of inpatient mortality. Patients transferred from another hospital were more likely to die in the hospital than patients admitted in a routine fashion (OR $5.0, p<0.001)$. Patients admitted emergently were more likely to die in the hospital than patients admitted on an elective basis (OR 2.8, $\mathrm{p}=0.04)$.

\section{Discussion}

We present the results of the first analysis of the relationship between patient, admission and NACHRI children's hospital designation for children undergoing craniotomy for malignant brain tumors using a large national database. We were able to capture 9360 discharges from 2000-2009 and report novel relationships between patient, admission, and hospital factors and the clinically relevant outcomes of discharge to home and mortality. We chose routine discharge as an outcome to differentiate patients who were able to go home from patients requiring 24-hour nursing care at a skilled nursing or long-term acute care facility, inpatient rehabilitation, or further inpatient care. A routine discharge suggests an uncomplicated postoperative discharge status allowing standard care at home, an outcome important to patients, parents, and medical professionals. We report an overall routine discharge rate of $83.6 \%$, which is lower than previously reported values. ${ }^{40}$ The in-hospital mortality rate of $1.3 \%$ was similar to mortality rates reported previously in other studies using other databases..$^{19,40}$

\section{Patient Factors}

Similar to prior studies ${ }^{19,40}$ we found that patients under 1 year of age were much less likely to have a routine discharge. We also report that patients under 1 year of age had a nonsignificant trend toward increased mortality, albeit with a large point estimate odds ratio of 6.9 -fold increase in mortality. The power of our analysis in this subgroup is limited due to the small sample size (425 children under 1 year of age) even in this large national database.

The potential difference noted in this group may be explained by evidence that malignant brain tumors in infants are histologically and genetically different from tumors in older children. The increased mortality of children under 1 year of age undergoing brain tumor treatment has been well documented. ${ }^{16,44}$ Many factors contribute to this outcome, including poor tolerance of chemotherapeutic agents and radiation as well as the prevalence of posterior fossa and deep hemispheric brain tumors in young children. ${ }^{15,16,45}$ In the Surveillance, Epidemiology and End Results (SEER) data reported by Hankinson et al., ${ }^{19}$ children under 1 year of age were much more likely to have intraventricular tumors, atypical teratoid/rhabdoid tumor, choroid plexus tumors, and desmoplastic infantile astrocytoma and less likely to have cerebellar tumors and juvenile pilocytic astrocytoma. Although frequencies of medulloblastoma were similar in infants and adults in the SEER data, with the advent of medulloblastoma subtyping, it has been reported that infants with medulloblastoma are much more likely to have the Shh subtype, which entails a worse prognosis, than the most favorable Wnt subtype. ${ }^{31}$ Another possibility is the limited access to advanced care in this group, as a recent analysis of Children's Oncology Group data showed lower-than-expected accrual of infants in clinical trials. ${ }^{30}$ Our analysis further supports the increased focus on infantile malignant brain tumors as targets for future research into treatment. As noted, there was a significantly increased rate of routine discharge in patients 10-17 years of age compared with 18 - to 20 -year-old patients. This may reflect early development of adult malignancies in patients approaching the 3rd decade of life. However, further data are required to assess this phenomenon.

Intraventricular, cerebellar, brainstem, and other tumor locations were independent predictors of nonroutine discharge but were not associated with mortality. This may be secondary to the more disabling effects of these tumors and increased need for further inpatient rehabilitation and nursing care even after tumor resection, a relationship that has been shown in the current literature. ${ }^{17,23,27,38,46}$ Our data indicate that the expected lengths of stay and postoperative regimens for patients with tumors in these locations will be prolonged compared with those for patients with hemispheric lesions.

\section{Admission Factors}

We also sought to analyze the relationship between admission factors and outcomes. Both admission source and admission type can provide an important window into utilization of a health care system. In our sample, 9.3\% of children were admitted as interfacility transfers, compared with $71.4 \%$ who were admitted electively or from the emergency room of the same facility. Even after controlling for other factors, we found that those children who were transferred from another hospital and underwent a craniotomy for malignant brain tumor had a 5-fold increase in the risk of mortality and were half as likely to be routinely discharged compared with those admitted electively. The adverse effect of interfacility transfer has been noted in other conditions such as ischemic stroke in adults ${ }^{43}$ and hemorrhagic stroke in children. ${ }^{1}$ In our report, we are able to control for important tumor variables such as location and patient variables such as age as well as other hospital factors such as procedural volume. We believe that this finding provides further support for the importance of centralizing care and early outpatient referrals to hospitals capable of providing definitive management for malignant brain tumors, rather than attempting to provide initial management at other facilities.

\section{Hospital Factors}

Initially, we sought to investigate the relationship between outcomes and treatment at a dedicated pediatric hospital, pediatric unit in a general hospital, or nonpediatric unit in a general hospital based on NACHRI classification. The NACHRI group includes 220 self-identified pediatric hospitals and specialized pediatric units in the United States. We found that even after controlling for 
important patient, admission and hospital factors such as size and procedural volume, patients undergoing craniotomy for malignant brain tumors at a pediatric hospital were more likely to have a routine discharge than patients treated at adult hospitals, regardless of whether that hospital had a pediatric unit. Larger hospital size and teaching status were also independently associated with increased rate of routine discharge. The effect of treatment at a designated pediatric hospital, independent of surgeon and hospital volume, has been seen in other pediatric general surgery conditions such as appendectomy. $9,10,14,17,19$, ${ }^{21,34}$ However, this is the first report, to our knowledge, of discharge outcome of neurosurgical patients at specialized pediatric hospitals.

Prior reports have attributed differences in outcomes after craniotomy for brain tumor ${ }^{40}$ and ventriculoperitoneal shunt placement ${ }^{8,41}$ to the effects of increased surgeon and hospital volume. A recent Norwegian study, however, has suggested that relationship between surgeon volume and outcome in pediatric brain tumor cases may be absent or even paradoxically adverse. ${ }^{42}$ Using an expanded model, we did note that procedural volume was not independently associated with discharge to home or mortality. We found that pediatric hospital designation, size, and teaching status were important explanatory factors. While increased procedural volume is ultimately associated with improved patient outcomes in univariate analysis, procedural volume drops out in our multivariate analysis as it is accounted for by the increased procedural volume inherent to treatment at children's hospitals.

Interestingly, treatment in a dedicated pediatric unit within an adult hospital was not shown to have improved outcomes compared with treatment in an adult hospital without a designated pediatric unit. This finding points to a possible fundamental difference between pediatric and nonpediatric hospitals and a pediatric hospital in terms of the tangible and intangible resources available. Accordingly, other factors beyond surgical experience and designation of a single unit for pediatric care are particularly important in the resection of pediatric malignant brain tumors. Recent advances in pediatric neurooncology care, including the availability of clinical trials and advanced medical therapy, have made specialized pediatric neurooncology increasingly important. ${ }^{33}$ It is likely that specialists in pediatric malignant brain tumors may centralize at designated pediatric hospitals. Studies further suggest higher likelihood of treatment by fellowshiptrained surgeons and critical care staff at pediatric hospitals. ${ }^{4,6,9,14,20,26,37,47}$ It is possible that the workflow, training of personnel, and availability of amenities geared toward children provide an inherent advantage for pediatric hospitals in providing care that may manifest as improved discharge outcomes. ${ }^{4,9}$ These findings are consistent with a recent meta-analysis of outcomes of specialization and volume in pediatric surgery, which found that rare and complex conditions (such as pediatric malignant brain tumors) are more likely to show hospital-level effects, while common conditions were more likely to show surgeonlevel volume effects. ${ }^{28}$

Importantly, we were not able to control for individual surgeon volume or subspecialization. The relationship between a neurosurgeon's specialization in pediatric neurosurgery and extent of resection for malignant pediatric brain tumors has previously been shown, although the effect of subspecialization could not be separated from the effect of surgeon volume. ${ }^{3}$ It is possible that the children's hospital designation may serve, in part, as a proxy for highly subspecialized pediatric neurosurgeons rather than larger groups of lower-volume surgeons.

We did not find a difference in mortality rates based on hospital factors. Adult neurosurgery and other complex surgical oncology procedures have shown differences in mortality based on hospital factors.$^{5-9,16}$ However, mortality was exquisitely rare in our series, despite the use of nationwide data from nearly a decade of discharges. Accordingly, it is uncertain whether any study could be sufficiently powered to detect differences in mortality in patients undergoing surgery for pediatric malignant brain tumors. We suggest that future research should be geared toward outcomes other than mortality.

\section{Limitations}

There are several limitations that are associated with the use of a national discharge database. Due to the nature of KID, we were unable to stratify outcomes based on surgeon volume, quality of postoperative care, and other patient- or provider-specific variables. Awareness of this additional factor may allow us to explain why institutions with a pediatric unit within a general hospital provide no additional benefit with respect to improved discharge outcomes. Addressing this issue, however, is very difficult because the KID does not include data on care after discharge or quality of postoperative care. Several other limitations also arise from using the KID itself, including difficulty in accounting for wide variations in physician practice, the 3-year nature of data collection, the lack of coding for illness severity, and the lack of patient characteristics, which have been highlighted in other studies that use the KID. ${ }^{18,24,32,36,39}$ Lastly, the accuracy of any administrative database is depending upon accurate coding and data entry.

\section{Conclusions}

The routine analysis of nationwide discharge databases can provide hypothesis-generating results across a variety of conditions. Our analysis of administrative data for pediatric patients with a malignant brain tumor revealed novel and potentially valuable targets for future research at the patient, admission, and hospital level. We add to the body of literature that suggests that infants younger than 1 year of age have a higher risk of mortality and this subgroup of patients will benefit from further research emphasis. We also provide a series of results that may have implications for further health care system development and specialization. NACHRI-designated children's hospitals were more likely to achieve routine discharges than non-NACHRIdesignated children's hospitals. Simply creating children's units within existing adult hospitals may not be sufficient to allow the highest quality of care for pediatric patients with malignant brain tumors. However, we are not able to specifically state which elements of specialized pediatric 
hospitals are most important in achieving better patient outcomes.

After controlling for other patient, hospital, and admission factors, we did not find an independent effect of volume on the outcome of treatment for pediatric malignant brain tumors. The absence of this effect could be due to limitations of the KID and administrative data sets. However, in this particular subfield, hospital volume is highly associated with other hospital factors such as hospital designation, size, teaching status, and location. Since the exact mechanism of the volume-outcome effect in neurosurgery is incompletely understood, further investigation into this area is warranted.

Unfortunately, both emergent admissions and patients transferred from other hospitals were less likely to have a routine discharge and more likely to die during their hospitalization. Superspecialization of all care to a handful of very large urban centers at the cost of increased interfacility transfers may not provide increased quality of care. It would seem that earlier referral before the critical point of illness could allow patients to be referred nonemergently to specialized centers. Larger referral networks and increased use of telemedicine may allow specialty pediatric hospitals to extend their reach into the community and funnel appropriate cases to specialty centers before the patients present to an emergency department in extremis. Striking the balance of appropriate specialty care for pediatric patients with malignant brain tumors will become an important challenge as the health care landscape evolves in the years to come.

\section{References}

1. Adil MM, Vidal GA, Beslow LA: Clinical outcomes among transferred children with ischemic and hemorrhagic strokes in the Nationwide Inpatient Sample. J Stroke Cerebrovasc Dis 25:2594-2602, 2016

2. Agency for Healthcare Research and Quality: Introduction to the HCUP Kids' Inpatient Databse (KID), 2009. HCUP User Support. (https://www.hcup-us.ahrq.gov/db/nation/kid/ kid_2009_introduction.jsp) [Accessed April 10, 2017]

3. Albright AL, Sposto R, Holmes E, Zeltzer PM, Finlay JL, Wisoff JH, et al: Correlation of neurosurgical subspecialization with outcomes in children with malignant brain tumors. Neurosurgery 47:879-887, 2000

4. Almond SL, Roberts M, Joesbury V, Mon S, Smith J, Ledwidge N, et al: It is not what you do, it is the way that you do it: impact of a care pathway for appendicitis. J Pediatr Surg 43:315-319, 2008

5. Begg CB, Cramer LD, Hoskins WJ, Brennan MF: Impact of hospital volume on operative mortality for major cancer surgery. JAMA 280:1747-1751, 1998

6. Birkmeyer JD, Stukel TA, Siewers AE, Goodney PP, Wennberg DE, Lucas FL: Surgeon volume and operative mortality in the United States. N Engl J Med 349:2117-2127, 2003

7. Casalino LP, Devers KJ, Brewster LR: Focused factories? Physician-owned specialty facilities. Health Aff (Millwood) 22:56-67, 2003

8. Cochrane DD, Kestle JR: The influence of surgical operative experience on the duration of first ventriculoperitoneal shunt function and infection. Pediatr Neurosurg 38:295-301, 2003

9. Collins HL, Almond SL, Thompson B, Lacy D, Greaney M, Baillie CT, et al: Comparison of childhood appendicitis management in the regional paediatric surgery unit and the district general hospital. J Pediatr Surg 45:300-302, 2010

10. Cosper GH, Hamann MS, Stiles A, Nakayama DK: Hospital characteristics affect outcomes for common pediatric surgical conditions. Am Surg 72:739-745, 2006

11. Cowan JA Jr, Dimick JB, Leveque JC, Thompson BG, Upchurch GR Jr, Hoff JT: The impact of provider volume on mortality after intracranial tumor resection. Neurosurgery 52:48-54, 2003

12. Cram P, Rosenthal GE, Vaughan-Sarrazin MS: Cardiac revascularization in specialty and general hospitals. N Engl J Med 352:1454-1462, 2005

13. Dobson A, Haught R, Sen N: Specialty heart hospital care: a comparative study. Am Heart Hosp J 1:21-29, 2003

14. Dudley RA, Johansen KL, Brand R, Rennie DJ, Milstein A: Selective referral to high-volume hospitals: estimating potentially avoidable deaths. JAMA 283:1159-1166, 2000

15. Duffner PK, Cohen ME, Myers MH, Heise HW: Survival of children with brain tumors: SEER Program, 1973-1980. Neurology 36:597-601, 1986

16. Duffner PK, Horowitz ME, Krischer JP, Burger PC, Cohen ME, Sanford RA, et al: The treatment of malignant brain tumors in infants and very young children: an update of the Pediatric Oncology Group experience. Neuro Oncol 1:152161, 1999

17. Gehan EA, Walker MD: Prognostic factors for patients with brain tumors. Natl Cancer Inst Monogr 46:189-195, 1977

18. Guthery SL, Hutchings C, Dean JM, Hoff C: National estimates of hospital utilization by children with gastrointestinal disorders: analysis of the 1997 kids' inpatient database. J Pediatr 144:589-594, 2004

19. Hankinson TC, Dudley RW, Torok MR, Patibandla MR, Dorris K, Poonia S, et al: Short-term mortality following surgical procedures for the diagnosis of pediatric brain tumors: outcome analysis in 5533 children from SEER, 2004-2011. J Neurosurg Pediatr 17:289-297, 2016

20. Hewitt M: Interpreting the Volume-Outcome Relationship in the Context of Health Care Quality. Workshop Summary. Washington, DC: National Academies Press, 2000

21. Hillner BE, Smith TJ, Desch CE: Hospital and physician volume or specialization and outcomes in cancer treatment: importance in quality of cancer care. J Clin Oncol 18:23272340,2000

22. Kosloske A, Coran A, Aronsson DD, Denslow GT, Hotaling AJ, Houck CS, et al: Guidelines for referral to pediatric surgical specialists. Pediatrics 110:187-191, 2002

23. Lagerwaard FJ, Levendag PC, Nowak PJ, Eijkenboom WM, Hanssens PE, Schmitz PI: Identification of prognostic factors in patients with brain metastases: a review of 1292 patients. Int J Radiat Oncol Biol Phys 43:795-803, 1999

24. Leventhal JM, Martin KD, Asnes AG: Incidence of fractures attributable to abuse in young hospitalized children: results from analysis of a United States database. Pediatrics 122:599-604, 2008

25. Long DM, Gordon T, Bowman H, Etzel A, Burleyson G, Betchen S, et al: Outcome and cost of craniotomy performed to treat tumors in regional academic referral centers. Neurosurgery 52:1056-1065, 2003

26. Luft HS, Hunt SS, Maerki SC: The volume-outcome relationship: practice-makes-perfect or selective-referral patterns? Health Serv Res 22:157-182, 1987

27. Mahaley MS Jr, Mettlin C, Natarajan N, Laws ER Jr, Peace BB: National survey of patterns of care for brain-tumor patients. J Neurosurg 71:826-836, 1989

28. McAteer JP, LaRiviere CA, Drugas GT, Abdullah F, Oldham KT, Goldin AB: Influence of surgeon experience, hospital volume, and specialty designation on outcomes in pediatric surgery: a systematic review. JAMA Pediatr 167:468-475, 2013 
29. Nallamothu BK, Rogers MA, Chernew ME, Krumholz HM, Eagle KA, Birkmeyer JD: Opening of specialty cardiac hospitals and use of coronary revascularization in Medicare beneficiaries. JAMA 297:962-968, 2007

30. Nooka AK, Behera M, Lonial S, Dixon MD, Ramalingam SS, Pentz RD: Access to Children's Oncology Group and Pediatric Brain Tumor Consortium phase 1 clinical trials: racial/ethnic dissimilarities in participation. Cancer 122:3207-3214, 2016

31. Northcott PA, Hielscher T, Dubuc A, Mack S, Shih D, Remke $\mathrm{M}$, et al: Pediatric and adult sonic hedgehog medulloblastomas are clinically and molecularly distinct. Acta Neuropathol 122:231-240, 2011

32. Odetola FO, Gebremariam A, Freed GL: Patient and hospital correlates of clinical outcomes and resource utilization in severe pediatric sepsis. Pediatrics 119:487-494, 2007

33. Qaddoumi I: Centralized services and large patient volumes are clinical necessities for a better outcome in pediatric brain tumors. Childs Nerv Syst 32:591-592, 2016

34. Raval MV, Cohen ME, Barsness KA, Bentrem DJ, Phillips JD, Reynolds M: Does hospital type affect pyloromyotomy outcomes? Analysis of the Kids' Inpatient Database. Surgery 148:411-419, 2010

35. Ries LAG, Smith MA, Gurney J, Linet M, Tamra T, Young J, et al (eds): Cancer Incidence and Survival Among Children and Adolescents: United States SEER Program 1975-1995. Bethesda, MD: National Cancer Institute, 1999

36. Schneier AJ, Shields BJ, Hostetler SG, Xiang H, Smith GA: Incidence of pediatric traumatic brain injury and associated hospital resource utilization in the United States. Pediatrics 118:483-492, 2006

37. Schrag D, Panageas KS, Riedel E, Cramer LD, Guillem JG, Bach PB, et al: Hospital and surgeon procedure volume as predictors of outcome following rectal cancer resection. Ann Surg 236:583-592, 2002

38. Simpson JR, Horton J, Scott C, Curran WJ, Rubin P, Fischbach J, et al: Influence of location and extent of surgical resection on survival of patients with glioblastoma multiforme: results of three consecutive Radiation Therapy Oncology Group (RTOG) clinical trials. Int J Radiat Oncol Biol Phys 26:239-244, 1993

39. Smink DS, Fishman SJ, Kleinman K, Finkelstein JA: Effects of race, insurance status, and hospital volume on perforated appendicitis in children. Pediatrics 115:920-925, 2005

40. Smith ER, Butler WE, Barker FG II: Craniotomy for resection of pediatric brain tumors in the United States, 1988 to 2000: effects of provider caseloads and progressive centralization and specialization of care. Neurosurgery 54:553565,2004

41. Smith ER, Butler WE, Barker FG II: In-hospital mortality rates after ventriculoperitoneal shunt procedures in the Unit- ed States, 1998 to 2000: relation to hospital and surgeon volume of care. J Neurosurg 100 (2 Suppl Pediatrics):90-97, 2004

42. Solheim O, Salvesen $\varnothing$, Cappelen J, Johannesen TB: The impact of provider surgical volumes on survival in children with primary tumors of the central nervous system - a populationbased study. Acta Neurochir (Wien) 153:1219-1229, 2011

43. Sonig A, Lin N, Krishna C, Natarajan SK, Mokin M, Hopkins LN, et al: Impact of transfer status on hospitalization cost and discharge disposition for acute ischemic stroke across the US. J Neurosurg 124:1228-1237, 2016

44. Stiller CA, Bunch KJ: Brain and spinal tumours in children aged under two years: incidence and survival in Britain, 1971-85. Br J Cancer Suppl 18:S50-S53, 1992

45. Suc E, Kalifa C, Brauner R, Habrand JL, Terrier-Lacombe MJ, Vassal G, et al: Brain tumours under the age of three. The price of survival. A retrospective study of 20 long-term survivors. Acta Neurochir (Wien) 106:93-98, 1990

46. Surawicz TS, Davis F, Freels S, Laws ER Jr, Menck HR: Brain tumor survival: results from the National Cancer Data Base. J Neurooncol 40:151-160, 1998

47. Welke KF, Diggs BS, Karamlou T, Ungerleider RM: The relationship between hospital surgical case volumes and mortality rates in pediatric cardiac surgery: a national sample, 1988-2005. Ann Thorac Surg 86:889-896, 2008

\section{Disclosures}

The authors report no conflict of interest concerning the materials or methods used in this study or the findings specified in this paper.

\section{Author Contributions}

Conception and design: Donoho, Wen, Liu, Zarabi, Christian, Cen, Mack, Attenello. Acquisition of data: Donoho, Wen, Liu, Zarabi, Christian, Cen, Mack, Attenello. Analysis and interpretation of data: Donoho, Wen, Liu, Zarabi, Christian, Mack, Attenello. Drafting the article: Donoho, Wen, Liu, Zarabi, Christian, McComb, Krieger, Mack, Attenello. Critically revising the article: Donoho, McComb, Krieger, Mack, Attenello, Zada. Reviewed submitted version of manuscript: Donoho, McComb, Mack, Attenello, Zada. Approved the final version of the manuscript on behalf of all authors: Donoho. Statistical analysis: Donoho, Cen.

\section{Correspondence}

Daniel A. Donoho, Department of Neurological Surgery, University of Southern California, GH 3300, 1200 N State St., Los Angeles, CA 90027. email: daniel.donoho@med.usc.edu. 